\title{
Mathematical Modeling of Heat, Mass and Moisture Transfer in Catalytic Porous Media
}

\author{
ANATOLIY VLASYUK ${ }^{1}$, VIKTOR ZHUKOVSKYY ${ }^{2}$, NATA2LIIA ZHUKOVSKA ${ }^{2}$, OLEG \\ PINCHUK , HESHAM RAJAB \\ ${ }^{1}$ Department of Economics, Mathematical Modeling and Information Technologies \\ The National University of Ostroh Academy \\ Ostroh, UKRAINE \\ ${ }^{2}$ Department of Computer Science and Applied Mathematics \\ The National University of Water and Environmental Engineering \\ Rivne, UKRAINE
}

\begin{abstract}
The discovery of ordered mesoporous materials has opened great opportunities for new applications in heterogeneous catalysis e.g. in soil purification processes. The focus of this study is the development of a mathematical model to simulate heat, mass and moisture transfer in soil arrays tacking into account catalytic micro- or nanoparticles. The nonlinear mathematical model of contaminant distribution in unsaturated catalytic porous media to the filter-trap in non-isothermal conditions is presented. The finite differences method was used to find the numerical solution of the corresponding boundary value problem and the analytical solution for mass transfer in catalytic microor nanoparticles was presented as well. Numerical experiments and their analysis were conducted using NanoSurface software complex.
\end{abstract}

Key-Words: mathematical model; boundary value problem; numerical method; nanoparticles, moisture transfer

Received: November 21, 2020. Revised: April 20, 2020. Accepted: May 1, 2020. Published: May 9, 2020.

\section{Introduction}

Pesticide use and the disposal of radioactive, biological, and chemical wastes can lead to much higher but localized levels of soil contamination [1, 2].

At the same time, researchers actively investigate heat, mass and moisture transfer processes on the meso- and micro levels. Modern industrial equipment allows the possibility to inject special nanoparticles into the soil with the purification purpose [3, 4]. Therefore, a lot of scientists around the world are involved into creation, developing, verification and validation of corresponding mathematical models for the fundamental understanding of the various processes of chemical and physical migration behaviour taking into account the catalytic micro- and nanoporous particles (catalytic porous media) [5-8].

On the other hand, the Ukrainian scientific school of underground mass transfer processes modelling have presented a range of mathematical models for problems of filtration consolidation [9], water cleaning in wetland [10], heat transfer in a greenhouses [11], iron removal from underground water [12], earth damps stresses-strained state [13, 14], moisture transport modeling under the conditions of sprinkling irrigation [15] etc.
Consequently, they prepared a good basement for next level of mathematical models which may connect macro- and micro-scaled processes of heat and mass transfer tacking into account their nonlinear dependencies.

\section{Problem Formulation}

Let us consider the problem of vertical migration of contaminants (e.g., fertilizers, pesticides, radionuclides etc) in a layer of soil (Fig. 1). The layer of soil is fulfilled with colloid adsorbents (e.g. sapropel) for the purification process [16]. That is why is called catalytic porous media.

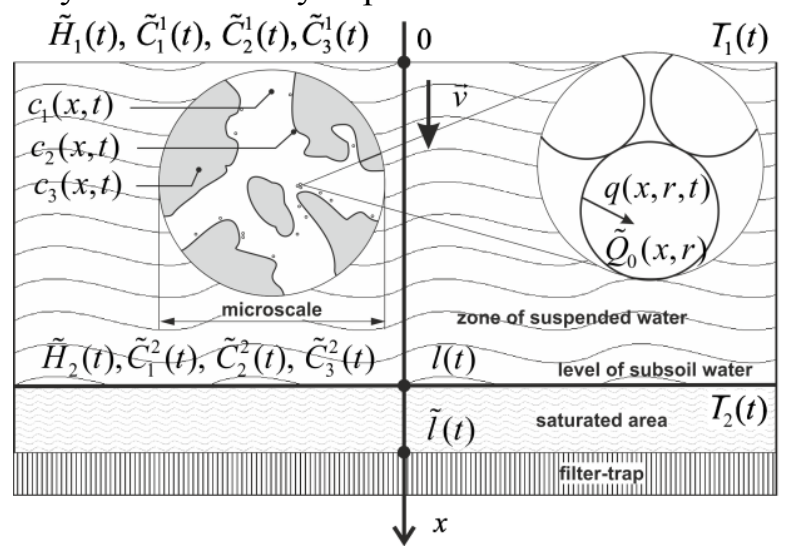

Figure 1. The process of contaminant migration to the filter-trap in the one-dimensional case 
The pore spaces between the soil grain particles are partially filled with water, partially with air (unsaturated zone or zone of suspended water).

At depth $\tilde{l}$ in the ground is a filter-trap filled with a sorbent (such as vermiculite) is located. The piezometric pressure and temperature on the upper and lower surfaces of the unsaturated zone $\tilde{H}_{1}(t)$, $\tilde{H}_{2}(t) \quad\left(\tilde{H}_{1}>\tilde{H}_{2}\right), \quad \tilde{T}_{1}(t)$ and $\tilde{T}_{1}(t)$ are specified respectively. The distribution of contaminant concentrations at the initial time $t=0: \tilde{C}_{1}^{0}(x)$, $\tilde{C}_{2}^{0}(x), \quad \tilde{C}_{3}^{0}(x)$, and $\tilde{Q}^{0}(x, r)$ are known. The contaminant concentrations $\tilde{C}_{1}^{1}(t), \tilde{C}_{2}^{1}(t)$ and $\tilde{C}_{3}^{1}(t)$ on the upper surface and $\tilde{C}_{1}^{2}(t), \tilde{C}_{2}^{2}(t), \tilde{C}_{3}^{2}(t)$ on the level of subsoil water are also known.

It is necessary to build an adequate mathematical model, find a numerical solution and develop software algorithm for further investigation of the $c_{1}(x, t), \quad c_{2}(x, t), \quad c_{3}(x, t) \quad$ and $\quad q(x, r, t)$ concentrations distribution on the large unsaturated area at a given time step.

\section{Mathematical Model}

Moisture, head and mass transfer of salts dissolved in water occurs under the influence of the pressure gradients and the concentration of salts. These moisture, mass and heat transfers of salt solutions occurs under the generalized Darcy's, Klutta's and Fick's laws.

Therefore, the boundary value problem of the contaminant migration in a catalytic porous medium in the one-dimensional nonlinear case was solved using a mathematical model with the following equations [17-20]:

the equation of contaminant migration with a concentration $c_{1}$ in a convectively mobile pore solution

$$
\begin{aligned}
\sigma_{1} \frac{\partial c_{1}}{\partial t}= & \frac{\partial}{\partial x}\left(D_{1}\left(c_{1}\right) \frac{\partial c_{1}}{\partial x}\right)+\frac{\partial}{\partial x}\left(D_{T_{1}} \frac{\partial T}{\partial x}\right)- \\
& -v\left(c_{1}\right) \frac{\partial c_{1}}{\partial x}-\gamma_{1} c_{1}+\gamma_{2} c_{2},
\end{aligned}
$$

the equation of contaminant migration with concentration $c_{2}$ located in the water-bound with the soil skeleton with account for the intraparticle transfer

$$
\begin{aligned}
\frac{\partial c_{2}}{\partial t}= & \frac{\partial}{\partial x}\left(D_{2}\left(c_{2}\right) \frac{\partial c_{2}}{\partial x}\right)+\frac{\partial}{\partial x}\left(D_{T_{2}} \frac{\partial T}{\partial x}\right)+ \\
& +\gamma_{1} c_{1}-\gamma_{2} c_{2}+\gamma_{3} c_{3}-\left.\tilde{\theta} \frac{\partial q}{\partial r}\right|_{r=R},
\end{aligned}
$$

the equation of contaminant migration with concentration $c_{3}$ located in the soil skeleton

$$
\begin{gathered}
\frac{\partial c_{3}}{\partial t}=\frac{\partial}{\partial x}\left(D_{3}\left(c_{3}\right) \frac{\partial c_{3}}{\partial x}\right)+\frac{\partial}{\partial x}\left(D_{T_{3}} \frac{\partial T}{\partial x}\right)+ \\
+\gamma_{2} c_{2}-\gamma_{3} c_{3}=\sigma_{1} \frac{\partial c_{3}}{\partial t},
\end{gathered}
$$

the equation of mass transfer of contaminant with a current concentration $q$ in micro- or nanoparticles

$$
D_{0}(q)\left(\frac{\partial^{2} q}{\partial r^{2}}+\frac{2}{r} \frac{\partial^{2} q}{\partial r}\right)+D_{T_{0}}\left(\frac{\partial^{2} T}{\partial r^{2}}+\frac{2}{r} \frac{\partial T}{\partial r}\right)=\frac{\partial q}{\partial t},
$$

the equation of convective heat transfer

$$
\frac{\partial}{\partial x}\left(\lambda_{T} \frac{\partial T}{\partial x}\right)-\rho c_{\rho} \mathrm{v} \frac{\partial T}{\partial x}=c_{T} \frac{\partial T}{\partial t},
$$

the equation of moisture transfer

$$
\begin{gathered}
\mu(h) \frac{\partial h}{\partial t}=\frac{\partial}{\partial x}\left(K\left(h, c_{1}, T\right) \frac{\partial h}{\partial x}\right)- \\
-\frac{\partial}{\partial x}\left(v_{c} \frac{\partial c_{1}}{\partial x}\right)-\frac{\partial}{\partial x}\left(v_{T} \frac{\partial T}{\partial x}\right)+f
\end{gathered},
$$

the generalized equation of the Darcy-Klutta law in nonisothermal conditions for moisture transfer of the salt solutions

$$
v=-K\left(h, c_{1}, T\right) \frac{\partial h}{\partial x}+v_{c}\left(c_{1}\right) \frac{\partial c_{1}}{\partial x}+v_{T} \frac{\partial T}{\partial x},
$$

the adsorption isotherm which at $\eta=0$ becomes the traditional Freundlich isotherm and at $\beta=1$ - the Langmuir isotherm

$$
\left.q(x, r, t)\right|_{r=R}=\frac{k_{f} \cdot c_{2}^{\beta}(x, t)}{1+\eta \cdot c_{2}^{\beta}(x, t)},
$$

boundary conditions for concentrations $c_{1}, c_{2}, c_{3}$, $q$ and piezometric head $h$

$$
\begin{gathered}
l_{1} c_{1}(0, t)=\tilde{C}_{1}^{1}(t), \quad l_{2} c_{1}(l, t)=\tilde{C}_{2}^{1}(t), \\
l_{3} c_{2}(0, t)=\tilde{C}_{1}^{2}(t), l_{4} c_{2}(l, t)=\tilde{C}_{2}^{2}(t), \\
l_{5} c_{3}(0, t)=\tilde{C}_{1}^{3}(t), l_{6} c_{3}(l, t)=\tilde{C}_{2}^{3}(t), \\
l_{5} T(0, t)=\tilde{T}_{1}(t), \quad l_{6} T(l, t)=\tilde{T}_{2}(t), \\
h(x, 0)=\tilde{H}_{0}(x), h(0, t)=\tilde{H}_{1}, h(l, t)=\tilde{H}_{2}, \\
T(x, 0)=\tilde{T}_{0}(x), c_{1}(x, 0)=\tilde{C}_{0}^{1}(x), \\
c_{2}(x, 0)=\tilde{C}_{0}^{2}(x), c_{3}(x, 0)=\tilde{C}_{0}^{3}(x), \\
\left.q\right|_{t=0}=\tilde{Q}^{0}(x, y, r),\left.\frac{\partial q(x, y, r, t)}{\partial r}\right|_{r=0}=0
\end{gathered}
$$

where $c_{1}(x, t), \quad D_{1}, \quad D_{T_{1}} \quad$ are concentration, coefficients of convective diffusion of contaminant and thermodiffusion in the moisture flow respectively; $c_{2}(x, t), D_{2}, D_{T_{2}}$ are concentration, coefficient of molecular diffusion of contaminant 
and thermodiffusion coefficient in water connected with soil skeleton; $c_{3}(x, t), \quad D_{3}, \quad D_{T_{2}}$ are concentration, coefficient of contaminant diffusion in soil skeleton and thermodiffusion coefficient; $q(x, r, t), D_{0}, D_{T_{0}}$ are concentration, the diffusion coefficient of contaminant and thermodiffusion coefficient in particles with radius $R$, which located in soil skeleton; $c_{T}$ and $c_{\rho}$ are the specific heats of solid and liquid phases; $\lambda_{T}$ is thermal conductivity; $K\left(h, c_{1}, T\right)$ is coefficient of moisture expansion; $\mu(h)$ is coefficient of moisture capacity; $k_{f}, \beta, \eta$ are adsorption isotherm coefficients; $\tilde{\theta}$ is coefficient of micro- or nanoparticle mass transfer influence on mass transfer near the ground skeleton; $v$ is moisture velocity; $\gamma_{1}, \gamma_{2}, \gamma_{3}$ are mass transfer coefficients; $v_{c}, v_{T}$ are coefficients of chemical and thermal osmosis; $\sigma_{1}$ is the porosity of soil; $x$ is vertical coordinate; $l_{i}, i=\overline{1,6}$ are differential operators for boundary conditions; $t$ is a time, $0<t<t_{1}, r$ is the radius (radial variable) $0<r<R$.

\section{Numerical Solution Algorithm}

The complicated boundary value problem (1)-(16) has been solved with different numerical approaches. The finite difference method was used in general. Therefore, the difference grid was introduced for the variables $x, r, t$ with the steps $h_{l}$, $h_{2}$, and $\tau$ accordingly:

$$
\omega_{h_{1} h_{2} \tau}=\left\{\begin{array}{l|l}
\left(x_{i}, r_{j}, t_{k}\right) & \begin{array}{l}
x_{i}=i h_{1}, r_{j}=j h_{2}, t_{k}=k \tau, \\
i=\overline{0, n_{1}}, j=\overline{0, n_{2}}, k=\overline{0, n_{3}}, \\
h_{1} n_{1}=l, r n_{2}=R, \tau n_{3}=T,
\end{array}
\end{array}\right\}
$$

Equations (1), (3), (5), (6), (7) have been discretized with the Samarskii monotonic difference scheme, an equation (2) with an implicit difference scheme.

Initially, we need to find out the piezometric head distribution $h(x, t)$ at each time step from the boundary value problem (6). The values of the piezometric head will differ, depending on the selection of the datum, but the difference between the values at the top and bottom of the layer will be the same and the Darcy velocity (7) depends only upon the difference in piezometric head $h(x, y)$.

Simultaneously we may calculate the temperature distribution $T(x, t)$ according to (5). Then we can find the distribution of $q(x, r, t), c_{3}(x, t), c_{2}(x, t)$ and $c_{1}(x, t)$ at different time steps sequentially.
To discretize equation (6), we use an implicit difference scheme [21]:

$$
\begin{gathered}
\frac{h_{i}^{(k+1)}-h_{i}^{(k)}}{\tau}= \\
=\frac{1}{\mu(h)}\left[\left(\frac{1}{h_{1}}\left(a_{i+1}^{(k+1)} \frac{h_{i+1}^{(k+1)}-h_{i}^{(k+1)}}{h_{1}}-a_{i}^{(k+1)} \frac{h_{i}^{(k+1)}-h_{i-1}^{(k+1)}}{h_{1}}\right)-\right.\right. \\
-\left(b_{i+1}^{(k+1)} \frac{c_{1, i+1}^{(k+1)}-c_{1, i}^{(k+1)}}{h_{1}}-b_{i}^{(k+1)} \frac{c_{1, i}^{(k+1)}-c_{1, i-1}^{(k+1)}}{h_{1}}\right)- \\
\left.\left.-\left(z_{i+1}^{(k+1)} \frac{T_{i+1}^{(k+1)}-T_{i}^{(k+1)}}{h_{1}}-z_{i}^{(k+1)} \frac{T_{i}^{(k+1)}-T_{i-1}^{(k+1)}}{h_{1}}\right)\right)+\tilde{f}_{i}^{(k)}\right], \\
i=\overline{1, n_{1}-1}, k=\overline{0, n_{3}-1}
\end{gathered}
$$

where

$$
\begin{aligned}
& \tilde{a}_{i}^{(k)}=\frac{1}{2}\left(K_{i}^{(k)}+K_{i-1}^{(k)}\right), \tilde{b}_{i}^{(k)}=\frac{1}{2}\left(\left(v_{c}\right)_{i}^{(k)}+\left(v_{c}\right)_{i-1}^{(k)}\right), \\
& \tilde{z}_{i}^{(k)}=\frac{1}{2}\left(\left(v_{T}\right)_{i}^{(k)}+\left(v_{T}\right)_{i-1}^{(k)}\right), \tilde{f}_{i}^{(k)}=f .
\end{aligned}
$$

To find the piezometric head distribution $h(x, t)$ from the difference equation (18) we use the Thomas algorithm [22]. To do this, we reduce the equation (18) to the next form

$$
a_{i} h_{i-1}^{(k+1)}-c_{i} h_{i}^{(k+1)}+b_{i} h_{i+1}^{(k+1)}=-F_{i}^{(k)},
$$

where

$$
\begin{gathered}
a_{i}=r^{\prime \prime} \tilde{a}_{i}^{(k+1)}, b_{i}=r^{\prime \prime} \tilde{a}_{i+1}^{(k+1)}, c_{i}=1+r^{\prime \prime}\left(\tilde{a}_{i}^{(k+1)}+\tilde{a}_{i+1}^{(k+1)}\right), \\
F_{i}^{(k)}=h_{i}^{(k)}-r^{\prime \prime}\left(s_{i}^{(k+1)}+g_{i}^{(k+1)}\right)+r^{\prime} \cdot \tilde{f}_{i}^{(k)}, \\
s_{i}^{(k+1)}=\tilde{b}_{i}^{(k+1)} c_{1, i-1}^{(k+1)}-\left(\tilde{b}_{i}^{(k+1)}+\tilde{b}_{i+1}^{(k+1)}\right) c_{1, i}^{(k+1)}+\tilde{b}_{i+1}^{(k+1)} c_{1, i+1}^{(k+1)}, \\
g_{i}^{(k+1)}=\tilde{z}_{i}^{(k+1)} T_{i-1}^{(k+1)}-\left(\tilde{z}_{i}^{(k+1)}+\tilde{z}_{i+1}^{(k+1)}\right) T_{i}^{(k+1)}+\tilde{z}_{i+1}^{(k+1)} T_{i+1}^{(k+1)} \\
r^{\prime}=\frac{\tau}{\mu(h)}, r^{\prime \prime}=\frac{r^{\prime}}{h_{1}^{2}} .
\end{gathered}
$$

It is easy to show that the stability conditions of the sweep method are fulfilled. The values of the piezometric head on each time layer $(k+l)$ are consistently found using the following relation

$$
h_{i}^{(k+1)}=\alpha_{i+1} h_{i+1}^{(k+1)}+\beta_{i+1}
$$

where $\quad \alpha_{i+1}^{1}=\frac{b_{i}^{1}}{\bar{c}_{i}^{1}-\alpha_{i}^{1} a_{i}^{1}}, \quad \beta_{i+1}^{1}=\frac{a_{i}^{1} \beta_{i}^{1}+c_{1, i}^{(k)}+F_{i}^{(k+1)}}{\bar{c}_{i}^{1}-\alpha_{i}^{1} a_{i}^{1}}$, $i=\overline{1, n_{1}-1}, \quad k=\overline{1, n_{3}}$.

The finite-difference analogue of the generalized equation of the Darcy law (7) in nonisothermal conditions has the following form:

$$
\begin{gathered}
\mathrm{v}_{i}^{(k)}=-K_{i}^{(k)}\left(c_{1, i}^{(k)}, T_{i}^{(k)}\right) \frac{h_{i+1}-h_{i-1}}{2 h_{1}}+ \\
+\left(v_{c}\right)_{i}^{(k)}\left(c_{1, i}^{(k)}\right) \frac{c_{1, i+1}^{(k)}-c_{1, i-1}^{(k)}}{2 h_{1}}+v_{T} \frac{T_{i+1}^{(k)}-T_{i-1}^{(k)}}{2 h_{1}}
\end{gathered}
$$




$$
i=\overline{1, n_{1}-1}, \quad k=\overline{1, n_{3}} \text {. }
$$

Let us also show the mathematical manipulation for the equation (1). At first, we have been written the finite-difference analogue of the corresponding differential equation (1):

$$
\begin{gathered}
\sigma_{1} \frac{c_{1, i}^{(k+1)}-c_{1, i}^{(k)}}{\tau}=\frac{\chi_{i}^{(k)}}{h_{1}}\left(d_{1, i+1}^{(k)} \frac{c_{1, i+1}^{(k+1)}-c_{1, i}^{(k+1)}}{h_{1}}-\right. \\
\left.-d_{1, i}^{(k)} \frac{c_{1, i}^{(k+1)}-c_{1, i-1}^{(k+1)}}{h_{1}}\right)+\frac{\left(r^{+}\right)_{i}^{(k)}}{D_{1, i}^{(k)}} d_{1, i+1}^{(k)} \frac{c_{1, i+1}^{(k+1)}-c_{1, i}^{(k+1)}}{h_{1}}+ \\
+\frac{\left(r^{-}\right)_{i}^{(k)}}{D_{1, i}^{(k)}} d_{1, i}^{(k)} \frac{c_{1, i}^{(k+1)}-c_{1, i-1}^{(k+1)}}{h_{1}}-\gamma_{1} c_{1, i}^{(k+1)}+\gamma_{2} c_{2, i}^{(k+1)}+ \\
+\frac{1}{h_{1}}\left(\left(d_{T_{1}}\right)_{i+1}^{(k)} \frac{T_{i+1}^{(k+1)}-T_{i}^{(k+1)}}{h_{1}}-\left(d_{T_{1}}\right)_{i}^{(k)} \frac{T_{i}^{(k+1)}-T_{i-1}^{(k+1)}}{h_{1}}\right),
\end{gathered}
$$

$$
\begin{gathered}
c_{1, i}^{(0)}=\tilde{C}_{1}^{0}\left(x_{i}\right), c_{1,0}^{(k)}=\tilde{C}_{1}^{1}\left(t_{k}\right), c_{1, n_{1}}^{(k)}=\tilde{C}_{1}^{2}\left(t_{k}\right), \\
i=\overline{1, n_{1}-1}, k=\overline{0, n_{3}} .
\end{gathered}
$$

The next notation was used here:

$$
\begin{aligned}
& d_{1, i}^{(k)}=\frac{D_{1, i}^{(k)}+D_{1, i-1}^{(k)}}{2}, D_{1, i}^{(k)}=D_{1}\left(c_{1, i}^{(k)}, T_{i}^{(k)}\right), \\
& \left(d_{T_{1}}\right)_{i}^{(k)}=\frac{\left(D_{T_{1}}\right)_{i}^{(k)}+\left(D_{T_{1}}\right)_{i-1}^{(k)}}{2}, r_{i}^{(k)}=\left(r^{+}\right)_{i}^{(k)}+\left(r^{-}\right)_{i}^{(k)}, \\
& \chi_{i}^{(k)}=\frac{1}{1+\frac{h_{1}\left|r_{i}^{(k)}\right|}{2 D_{1, i}^{(k)}}}=1-\frac{h_{1}\left|r_{i}^{(k)}\right|}{2 D_{1, i}^{(k)}}+O\left(h_{1}^{2}\right), \\
& \left(r^{+}\right)_{i}^{(k)}=\frac{-v_{i}^{(k)}+\left|\cup_{i}^{(k)}\right|}{2} \geq 0,\left(r^{-}\right)_{i}^{(k)}=\frac{-\cup_{i}^{(k)}-\left|\cup_{i}^{(k)}\right|}{2} \leq 0 .
\end{aligned}
$$

Thomas algorithm was used for calculating the distribution of the $c_{1}(x, t)$ salt concentration. And the difference scheme (21)-(22) consequently was presented in the next form:

$$
\left\{\begin{array}{l}
a_{i}^{1} c_{1, i-1}^{(k+1)}-\bar{c}_{i}^{1} c_{1, i}^{(k+1)}+b_{i}^{1} c_{1, i+1}^{(k+1)}=-c_{1, i}^{(k)}-f_{i}^{1,(k+1)}, \\
c_{1,0}^{(k+1)}=\mu_{1}^{1} c_{1,1}^{(k+1)}+\mu_{2}^{1}, \\
c_{1, n_{1}}^{(k+1)}=\mu_{3}^{1} c_{1, n_{1}-1}^{(k+1)}+\mu_{4}^{1},
\end{array}\right.
$$

where

$$
a_{i}^{1}=\frac{\tau}{\sigma_{1}} \frac{d_{1, i}^{(k)}}{h_{1}}\left(\frac{\chi_{i}^{(k)}}{h_{1}}-\frac{\left(r^{-}\right)_{i}^{(k)}}{D_{1, i}^{(k)}}\right),
$$

$$
\begin{gathered}
b_{i}^{1}=\frac{\tau}{\sigma_{1}} \frac{d_{1, i+1}^{(k)}}{h_{1}}\left(\frac{\chi_{i}^{(k)}}{h_{1}}+\frac{\left(r^{+}\right)_{i}^{(k)}}{D_{1, i}^{(k)}}\right), \\
\bar{c}_{i}^{1}=1+\frac{\tau}{\sigma_{1}}\left(\frac{\chi_{i}^{(k)}\left(d_{1, i+1}^{(k)}+d_{1, i}^{(k)}\right)}{h_{1}^{2}}+\right. \\
\left.+\frac{1}{h_{1} D_{1, i}^{(k)}}\left(\left(r^{+}\right)_{i}^{(k)} d_{1, i+1}^{(k)}-\left(r^{-}\right)_{i}^{(k)} d_{1, i}^{(k)}\right)+\gamma_{1}\right), \\
f_{i}^{1,(k+1)}=\frac{\tau}{\sigma_{1}}\left(\gamma_{2} c_{2, i}^{(k+1)}+\frac{1}{h_{1}}\left(\left(d_{T_{1}}\right)_{i+1}^{(k)} \frac{T_{i+1}^{(k+1)}-T_{i}^{(k+1)}}{h_{1}}-\right.\right. \\
\left.\left.--\left(d_{T_{1}}\right)_{i}^{(k)} \frac{T_{i}^{(k+1)}-T_{i-1}^{(k+1)}}{h_{1}}\right)\right), \\
\mu_{1}^{1}=0, \mu_{2}^{1}=\tilde{C}_{1}^{1}, \mu_{3}^{1}=0, \mu_{4}^{1}=\tilde{C}_{1}^{2} .
\end{gathered}
$$

Finally, the $c_{1}(x, t)$ salt concentration distribution at time level $(k+1)$ may be presented with the following relation:

$$
c_{1, i}^{(k+1)}=\alpha_{i+1}^{1} c_{1, i+1}^{(k+1)}+\beta_{i+1}^{1},
$$

where $\alpha_{i+1}^{1}=\frac{b_{i}^{1}}{\bar{c}_{i}^{1}-\alpha_{i}^{1} a_{i}^{1}}, \quad \beta_{i+1}^{1}=\frac{a_{i}^{1} \beta_{i}^{1}+c_{1, i}^{(k)}+f_{i}^{1,(k+1)}}{\bar{c}_{i}^{1}-\alpha_{i}^{1} a_{i}^{1}}$, $i=\overline{1, n_{1}-1}, \quad k=\overline{1, n_{3}}, \quad \alpha_{1}^{1}=\mu_{1}^{1} \equiv 0, \quad \beta_{1}^{1}=\mu_{2}^{1} \equiv \tilde{C}_{1}^{1}$.

Thus, the Thomas algorithm was used to solve such kind of tridiagonal system of equations [22].

Analogical mathematical manipulations were provided for equations (3), (5), (6), (7) and (2). Some of them described in details in the following papers $[18,23]$. For intraparticle contaminant concentration analysis (4) may be used as numerical finite-difference analysis as well as analytical. Let us show the steps for the situation when $D_{0}(q)=D_{0}=$ const and $D_{T_{3}}=0$. Thus we can obtain:

$$
\frac{\partial q}{\partial t}=D_{0}\left(\frac{\partial^{2} q}{\partial r^{2}}+\frac{2}{r} \frac{\partial^{2} q}{\partial r}\right),
$$

The solution of (25) with appropriate boundary conditions $q(x, r, 0)=\tilde{Q}_{0}(r)$ and $q(x, R, t)=0$ can be found analytically:

$$
q(x, r, t)=\frac{1}{r} \sum_{n=1}^{\infty} \beta_{n} e^{-\frac{n^{2} \pi^{2} D_{0} t}{R^{2}}} \sin \frac{n \pi r}{R},
$$

where

$$
\beta_{n}=\frac{2}{R} \int_{0}^{R} r \tilde{Q}_{0}(r) \sin \frac{n \pi r}{R} d r .
$$

Let us find the analytical solution (25) for the case where the boundary condition is not homogenous:

$$
q(x, R, t)=\tilde{Q}_{1},
$$

where $\tilde{Q}_{1}=$ const . 
To reduce the nonhomogeneous boundary condition to homogeneous boundary condition, we use the following substitution:

$$
q(x, r, t)=u(x, r, t)+\tilde{Q}_{1},
$$

where $u(x, r, t)$ is the unknown function. Then

$$
\begin{gathered}
\frac{\partial q}{\partial t}=\frac{\partial u}{\partial t}, \frac{\partial^{2} q}{\partial r^{2}}=\frac{\partial^{2} u}{\partial r^{2}}, \frac{\partial q}{\partial r}=\frac{\partial u}{\partial r}, \\
q(x, R, t)=u(x, R, t)+\tilde{Q}_{1}=\tilde{Q}_{1}, \\
q(x, r, 0)=u(x, r, 0)+\tilde{Q}_{1}=\tilde{Q}_{0}(r) .
\end{gathered}
$$

And hence

$$
\begin{gathered}
u(x, R, t)=0, \\
u(x, r, 0)=\tilde{Q}_{0}(r)-\tilde{Q}_{1} .
\end{gathered}
$$

Thus, we have the following boundary value problem for the function $u(x, r, t)$ :

$$
\begin{gathered}
\frac{\partial u}{\partial t}=D_{0}\left(\frac{\partial^{2} u}{\partial r^{2}}+\frac{2}{r} \frac{\partial u}{\partial r}\right), \mathbf{X} \in \Omega, r \in(0, R), t>0 \\
u(x, r, 0)=\tilde{Q}_{0}(r)-\tilde{Q}_{1}, \mathbf{X} \in \Omega, r \in(0, R) \\
u(x, R, t)=0, \mathbf{X} \in \Omega, t>0
\end{gathered}
$$

And the solution of (29)-(31) is the following:

$$
u(x, r, t)=\frac{1}{r} \sum_{n=1}^{\infty} \beta_{n} e^{-\frac{n^{2} \pi^{2} D_{0} t}{R^{2}}} \sin \frac{n \pi r}{R},
$$

where

$$
\beta_{n}=\frac{2}{R} \int_{0}^{R} r\left(\tilde{Q}_{0}(r)-\tilde{Q}_{1}\right) \sin \frac{n \pi r}{R} d r
$$

Returning to the replacement (7), we obtain the analytical solution (25) with the appropriate boundary conditions in the form of the following function:

$$
q(x, r, t)=\tilde{Q}_{1}+\frac{1}{r} \sum_{n=1}^{\infty} \beta_{n} e^{-\frac{n^{2} \pi^{2} D_{0} t}{R^{2}}} \sin \frac{n \pi r}{R}
$$

where

$$
\beta_{n}=\frac{2}{R} \int_{0}^{R} r\left(\tilde{Q}_{0}(r)-\tilde{Q}_{1}\right) \sin \frac{n \pi r}{R} d r .
$$

\section{Software Implementation and Numerical Experiments}

The process phenomenon being studied was researched via cross-platform NanoSurface software package. This our tool was developed with a $\mathrm{C}++$ programming language and Qt framework for different underground processes computer simulation [24]. The application has a suitable graphical user interface (GUI) that allow users to enter the required initial data (diffusion coefficients, boundary conditions, etc.), select appropriate mathematical model, perform necessary calculation and analyze received data using 2D/3D curves and concentration tables $\left(c_{1}(x, t), c_{2}(x, t), c_{3}(x, t)\right.$, $q(x, r, t))$. User can easily export all received data for future processing. We added necessary classes for the NanoSurface software package for performing computer modelling of the physical problem described above. Currently Nanusurface performs all calculations via finite-difference method engine but in near future it is planned to implement finite element method [25].

For our experiments we used the following input data [26]:

$$
\begin{aligned}
& l=10 m, \tilde{H}_{1}=0.1 m, \tilde{H}_{2}=0.01 m, \sigma_{1}=0.25, \\
& \tau=30 \text { days }, \gamma_{1}=\gamma_{2}=0.0065, R=5 \cdot 10^{-8} \mathrm{~m}, \beta=1 \text {, } \\
& \eta=0, k_{f}=1, D_{1}=2 \cdot 10^{-3} \frac{\mathrm{m}^{2}}{d a y}, D_{2}=1 \cdot 10^{-5} \frac{\mathrm{m}^{2}}{d a y}, \\
& \tilde{C}_{1}^{1}(t)=5 \frac{\kappa 2}{\mathcal{M}^{3}}, \quad \tilde{C}_{1}^{2}(t)=0 \frac{\mathrm{kg}}{\mathrm{m}^{3}}, \quad \tilde{C}_{2}^{1}(t)=5 \frac{\mathrm{kg}}{\mathrm{m}^{3}}, \\
& \tilde{C}_{2}^{2}(t)=0 \frac{\mathrm{kg}}{\mathrm{m}^{3}}, \quad \tilde{C}_{1}^{0}(x)=5 \frac{\mathrm{kg}}{\mathrm{m}^{3}}, \quad \tilde{C}_{2}^{0}(x)=5 \frac{\mathrm{kg}}{\mathrm{m}^{3}}, \\
& \tilde{Q}^{0}(x, r)=0 \frac{\mathrm{kg}}{\mathrm{m}^{3}}, \tilde{\theta}=0.05 \\
& c_{\rho}=4,2 \frac{\mathrm{kJ}}{\mathrm{kg} \cdot{ }^{\circ} \mathrm{C}}, c_{T}=2137 \frac{\mathrm{kJ}}{\mathrm{m}^{3} \cdot{ }^{\circ} \mathrm{C}}, \lambda_{T}=108 \frac{\mathrm{kJ}}{\mathrm{m} \cdot{ }^{\circ} \mathrm{C} \cdot \mathrm{day}}, \\
& \tilde{T}_{2}(t)=5^{\circ} C, \tilde{T}_{0}(x)=1^{\circ} C, \tilde{T}_{1}(t)=20^{\circ} C, \\
& \rho=1 \cdot 10^{3} \frac{\mathrm{kg}}{\mathrm{m}^{3}}, D_{T}=1 \cdot 10^{-4} \frac{\mathrm{m}^{2}}{\text { day }}, \\
& \mu(h)=\frac{\partial \theta}{\partial h}=\frac{0.23}{4.5} \cdot \exp ((h+x) \cdot 1.5), \\
& K(\theta)=K_{f} \cdot \exp \left(\frac{3.5}{1.5}(h+x)\right) \text {. }
\end{aligned}
$$

Usually, in the case of laminar filtration the coefficient of convective diffusion may be presented in linear dependence from the filtration rate [27]:

$D_{1, i}^{(k)}=D_{\mu}+\lambda\left|\mathrm{v}_{i}^{(k)}\right|, \quad i=\overline{1, n_{1}-1}, \quad k=\overline{1, n_{3}}$,

where $D_{\mu}$ is the coefficient of molecular diffusion in a porous medium and $\lambda$ is the dispersion parameter. We adopt the following dependence of the filtration rate $K_{f}\left(c_{1}, T\right)$ on the concentration of the salt solution and soil temperature. This information presented in [18]. 


\section{Analysis of Computational Results}

We obtained the graphs of the piezometric head (Fig. 2), fields of moisture velocity $v(x, t)$ (Fig. 3), temperature $T(x, t)$ (Fig. 4) and the distribution of $c_{1}(x, t), c_{2}(x, t)$ and salt solutions concentration over the unsaturated region over the time (Fig. 4).

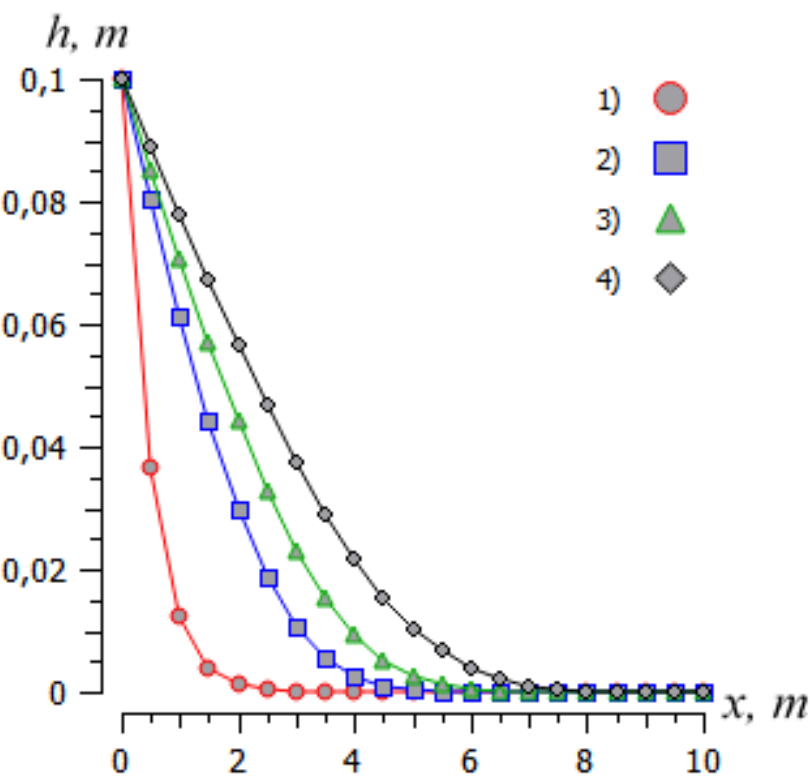

Figure 2. Distribution of piezometric head $h(x)$ at different time steps: 1) 30 days; 2) 1 year; 3) 2 years; 50 months.

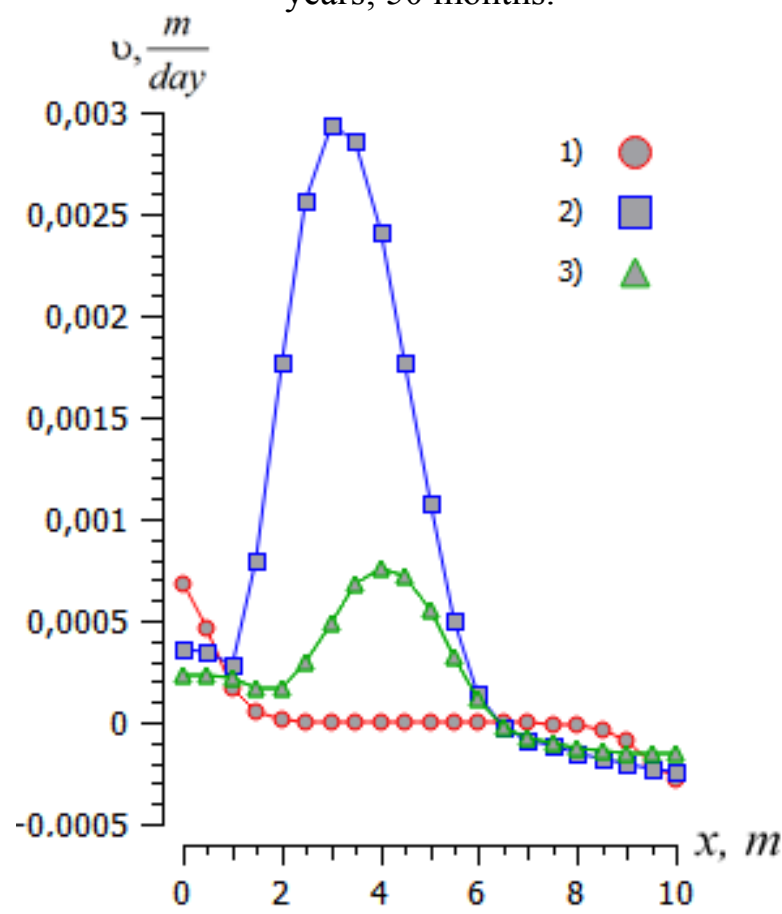

Figure 3. Distribution of moisture velocity $v(x)$ for nonlinear dependence of the moisture factor $K_{f}=K_{f}\left(x, c_{1}\right)$ at different time steps: 1) 30 days; 2) 1 year; 3) 2 years.
The flow of the pore water (Fig. 4) in both saturated and unsaturated soil depends on the piezometric head. That is to say, when the difference in piezometric head between two points is zero, the pore water is under the hydrostatic condition and does not flow. On the other hand, when the difference in piezometric head between two points is not zero, the pore water is under the hydrodynamic condition and the pore water flows in soil irrespective of saturated and unsaturated conditions. It means that the piezometric head is one of the most important physical quantities for the pore water in the soil.

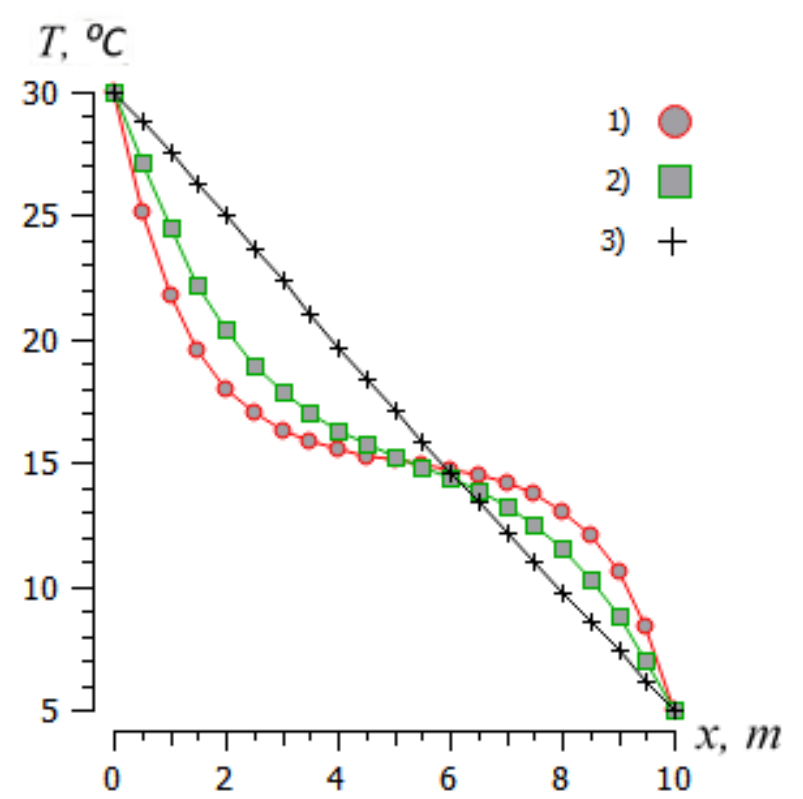

Figure 4. Temperature distribution $T(x)$ at different time steps: 1) 30 days; 2) 2 mounths; 3) 1 year.

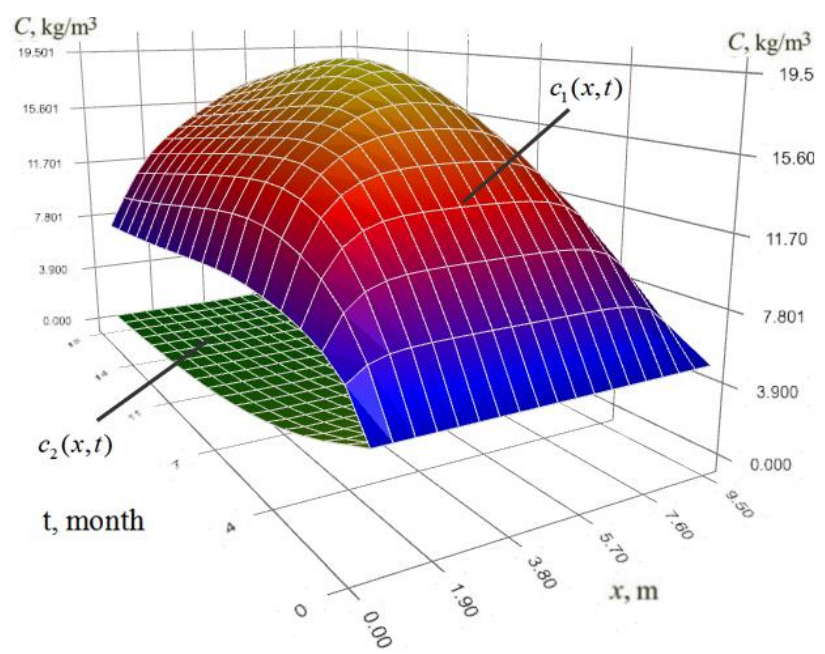

Figure 5. Comparative distribution of concentrations $c_{1}(x, t)$ and $c_{2}(x, t)$ depending on the depth of the soil layer $x$ over the time $t$. 


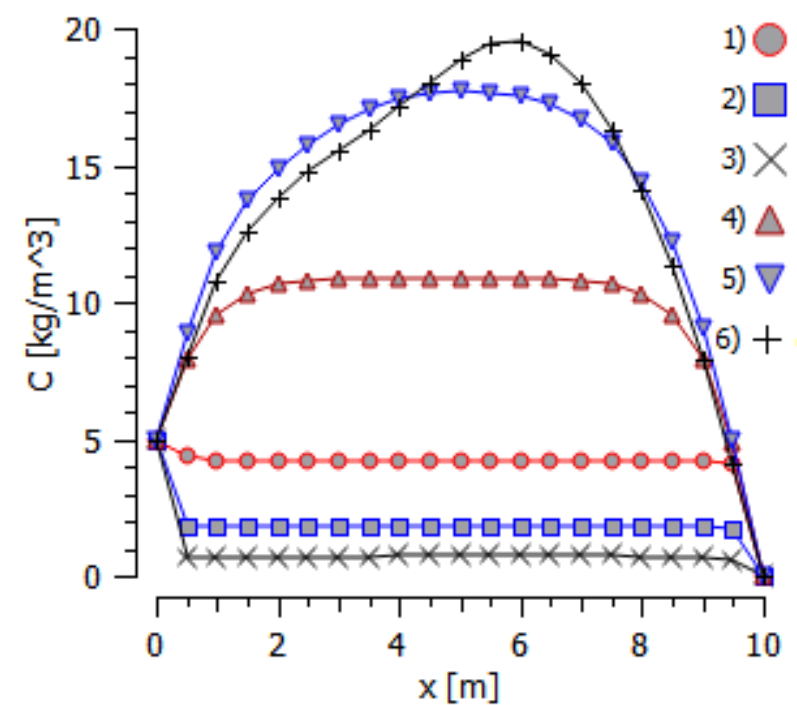

Figure 7. Comparative distribution of concentrations $c_{1}(x)$ (graphs $\left.4,5,6\right)$ and $c_{2}(x)$ (graphs $1,2,3$ ) taking into account mass transfer in microparticles at different time steps: 1) 30 days; 2) 0.5 year; 3) 1 year.

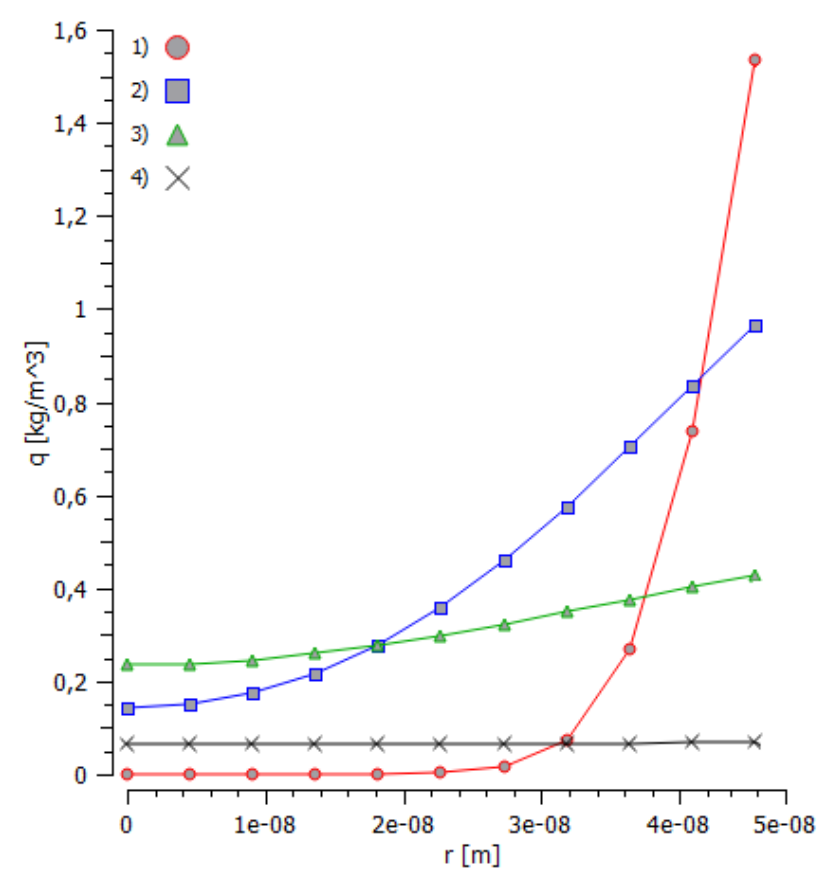

Figure 7. Distribution of concentration $q(x, r, t)$ in microparticles at depth $1 m$ from the top at different time steps: 1) 30 days; 2) 0.5 year; 3) 1 year; 4) 3 years.

The influence of microparticles on overall mass transfer has become obvious. The presence of sorbent microparticles with specific characteristic in the ground may accelerates up to $10 \%$ the process of cleaning the soil drought from pollution.

\section{Conclusion}

The physical problem of soil purification according to agroindustry requirements and critical analysis of several scientific papers was formulated. The nonlinear mathematical model of the contaminant vertical migration in unsaturated catalytic porous media to the filter-trap in isothermal conditions was defined. Catalytic porous media were presented with colloid nano adsorbents (e.g. sapropel). The mathematical model took into account the micro and the meso/macro scale factors of the heat mass and moisture transfer processes. Numerical and analytical solutions of the complicated boundary value problem have been proposed. The necessary classes for the NanoSurface software package were developed and the numerical experiments with their analysis have been conducted.

\section{References:}

[1] M. Thomas E., B.-H. Shannon L., O. Mira S., and T. Fred D., "Mass transport within soils," pp. 159-211, 2010.

[2] M. MacLeod, T. Gouin, and T. E. McKone, "Modeling in environmental chemistry," Environmental science. Processes \& impacts, vol. 20, no. 1, pp. 10-11, 2018, doi: 10.1039/c8em90001a.

[3] M. Auffan et al., "Nanomaterials as adsobents," (in af), Environmental Nanotechnology: Applications and Impacts of Nanomaterials, McGraw-Hill, New York, pp. 371-392, 2007.

[4] A. Giniatoulline, "Mathematical Modeling of the Rotating Stratified Fluid in a Vicinity of the bottom of the Ocean," International journal of Mechanics, vol. 13, pp. 149-155, 2019.

[5] P. Kostrobij, B. Markovych, O. Viznovych, and M. Tokarchuk, "Generalized diffusion equation with fractional derivatives within Renyi statistics," Journal of Mathematical Physics, vol. 57, no. 9, p. 93301, 2016, doi: 10.1063/1.4962159.

[6] W. C. Conner and J. P. Fraissard, Fluid transport in nanoporous materials. Dordrecht, the Netherlands: Springer in cooperation with NATO Public Diplomacy Division, 2006.

[7] A. Guessab and A. Aris, "Numerical Analysis of CPU with Heat Sink base of Copper Core using CFD," International journal of Mechanics, vol. 13, pp. 144-148, 2019.

[8] M. Petryk, I. Boyko, M. Petryk, J. Fraissard, and I. Mudryk, "Modeling of adsorption and desorption of hydrocarbons in nanoporous catalytic zeolite media using nonlinear Langmuir isotherm," in Fourteenth 
International Conference on Correlation Optics, Chernivtsi, Ukraine, 2019, p. 42.

[9] A. P. Vlasyuk and P. M. Martynyuk, "Numerical solution of three-dimensional problems of filtration consolidation with regard for the influence of technogenic factors by the method of radial basis functions," J Math Sci, vol. 171, no. 5, pp. 632-648, 2010, doi: 10.1007/s10958-010-0163-z.

[10] V. Moshynskyi, V. Filipchuk, N. Ivanchuk, and P. Martyniuk, "Computer modeling of water cleaning in wetland taking into account of suffosion ang colmatation," EEJET, vol. 1, 10 (91), pp. 38-43, 2018, doi: 10.15587/17294061.2018.123455.

[11] V. Hud, I. Gerasimov, P. Martyniuk, O. Pinchuk, and P. Volk, "Mathematical modelling of heat transfer in a greenhouse with surface soil heating system," Przeglad Naukowy Inżynieria $i$ Ksztaltowanie Środowiska, vol. 28, no. 4, pp. 569-583, 2019, doi: 10.22630/PNIKS.2019.28.4.52.

[12] V. Orlov, A. Safonyk, S. Martynov, and S. Kunytskyi, "Simulation the process of iron removal the underground water by polystyrene foam filters," Int. J. of Pure and Appl. Math., vol. 109, no. 4, 2016, doi: 10.12732/ijpam.v109i4.11.

[13] A. P. Vlasyuka and N. A. Zhukovskaya, "Mathematical Simulation of the Stressed-Strained State of the Foundation of Earth Dams with an Open Surface Under the Influence of Heat and Mass Transfer in the Two-Dimensional Case," Journal of Engineering Physics and Thermophysics, vol. 88, no. 2, pp. 329-341, 2015, doi: 10.1007/s10891-0151197-3.

[14] A. P. Vlasyuk, Borowik B, Zhukovska, N. A., V. V. Zhukovskyy, and Karpinskyi V, "Computer modelling of heat and mass transfer effect on the three-dimensional stressedstrained state of soil massif," 18th International Multidisciplinary Scientific Geoconference SGEM 2018, vol. 18, 1.2, pp. 153-160, 2018.

[15] M. I. Romashchenko, V. O. Bohaienko, T. V. Matiash, V. P. Kovalchuk, and I. I. Danylenko, "Influence of evapotranspiration assessment on the accuracy of moisture transport modeling under the conditions of sprinkling irrigation in the south of Ukraine," Archives of Agronomy and Soil Science, vol. 1, no. 2, pp. 1-12, 2019, doi: $10.1080 / 03650340.2019 .1674445$.

[16] K. Stankevica, "Organic Rich freshwater Sediments (Sapropel) as Potential Soil Amendment for Recultivation of Areas Contaminated with Heavy Metals," in 13th
SGEM GeoConference on Water Resources, Forest, Marine and Ocean Ecosystems, 2013.

[17] J. Kärger, D. M. Ruthven, and D. N. Theodorou, Diffusion in nanoporous materials. Weinheim, Germany: Wiley-VCH, 2012.

[18] A. P. Vlasyuk and V. V. Zhukovskii, "Mathematical Simulation of the Migration of Radionuclides in a Soil Medium Under Nonisothermal Conditions with Account for Catalytic Microparticles and Nonlinear Processes," Journal of Engineering Physics and Thermophysics, vol. 90, no. 6, pp. 13861398, 2017, doi: 10.1007/s10891-017-1697-4.

[19] B. M. Budak, A. A. Samarskii, A. N. Tikhonov, I. N. Sneddon, M. Stark, and S. Ulam, A Collection of Problems on Mathematical Physics: International Series of Monographs in Pure and Applied Mathematics: Elsevier Science, 2013.

[20] A. Vlasyuk and I. Ilkiv, "Mathematical and Computer Simulation of the Interconnected Processes Mass, Heat and Moisture Transfer in Horizontal Soil Media," MCIT, no. 3, pp. 8283, 2019, doi: 10.31713/MCIT.2019.49.

[21] A. A. Samarskii, The theory of difference schemes. New York: Marcel Dekker, 2001.

[22] G. I. Marchuk, Methods of Numerical Mathematics, 2nd ed. New York, NY: Springer Verlag, 1982.

[23] A. P. Vlasyuk, R. V. Kochan, V. V. Zhukovskyy, and N. A. Zhukovska, "Mathematical and computer modeling of contaminant migration to filter trap in twodimensional nonlinear case," 18th International Multidisciplinary Scientific Geoconference SGEM 2018, vol. 18, 2.2, pp. 293-300, 2018.

[24] A. P. Vlasyuk and V. V. Zhukovskyy, "Nanosurfacea tool for computer modeling of mass transfer process in catalityc porous media," Abstracts of XXVIII International Conference "Problems of decision making under uncertainties”, pp. 122-124, 2016.

[25] A. Chiappa, C. Groth, and M. E. Biancolini, "Improvement of 2D Finite Element Analysis Stress Results by Radial Basis Functions and Balance Equations," International journal of Mechanics, vol. 13, pp. 90-99, 2019.

[26] I. I. Liashko, L. I. Demchenko, and G. E. Mistetskii, Chislennoe reshenie zadach teplo- $i$ massoperenosa $v$ poristykh sredakh. Kiev: Nauk. dumka, 1991.

[27] V. Entov, S. Numerov, P. PolubarinovaKochina, and I. Charnyi, Development of Investigations on the Theory of Filtration in the USSR (1917-1967). Moscow: Nauka, 1969. 